\title{
Fast removal of pollutants from vehicle emissions during cold-start stage
}

https://doi.org/10.1515/chem-2018-0041

received November 26, 2017; accepted March 2, 2018.

Abstract: Recently, enormous research passion has been devoted to reduce air pollution caused by vehicle emissions. Effective vehicle emission control method is to convert exhaust pollutants by placing catalyst in the exhaust pipe. However, the major stumbling block is that a large portion of emission occurs in the initial 20-30 s during the engine cold-start stage, before catalyst can reach its operating temperature. To address the challenge, herein we developed a catalyst utilizing $\mathrm{Pd}$ and $\mathrm{Rh}$ as active components, Ce-Zr solid solution as assistant, $\mathrm{Y}-\mathrm{Al}_{2} \mathrm{O}_{3}$ as coating and $\mathrm{Fe}-\mathrm{Cr}-\mathrm{Al}$ as supporter. The catalyst component was optimized (atom ratio of Ce: $\mathrm{Zr}$ is 6:4, mass ratio of $\mathrm{Pd}: \mathrm{Rh}$ is $8: 2$, total weight of $\mathrm{Pd}$ and $\mathrm{Rh}$ is 1.2 $\mathrm{g} / \mathrm{L}$, pore density is 700 pores/inch ${ }^{2}$ ) and high-frequency electrical heating technique was employed to decrease operating temperature from $400^{\circ} \mathrm{C}$ to $350^{\circ} \mathrm{C}$ and improve exhaust conversion efficiency by $78 \%$.

Keywords: Vehicle exhaust; Emission control catalyst; High-frequency electrical heating; Engine cold-start stage.

\section{Introduction}

Hydrocarbons (HCs), nitrogen oxides $\left(\mathrm{NO}_{\chi}\right)$, carbon oxides (CO), which result from vehicle exhaust and industrial combustion of fossil fuels, are major air pollutants [1-2]. They contribute to a variety of harmful environmental effects, such as smog and acid rain [3-4], and threaten people's life [5]. It is reported that $90 \%$ of the pollutant in nine Chinese cities comes from vehicle exhaust, industrial

*Corresponding author: Jia Hui Li, Feng Qian: No.2 Secondary School Attached to East China Normal University, No.555, Chen Hui Road, Pu Dong New District, Shanghai 201203, PR China, E-mail: jiahuili@ ecnu.edu.cn; qianfeng@ecnu.edu.cn

Ran Wang: No.2 Secondary School Attached to East China Normal University, No.555, Chen Hui Road, Pu Dong New District, Shanghai 201203, PR China manufacture, coal burning, and vehicle exhaust is the primary pollution source [6]. The reduction of vehicle exhaust has become one of the greatest challenges in environmental protection [7-12].

To date, scientists have developed several traditional vehicle exhaust control methods: electrical heating catalyst, second air injection system, exhaust gas recirculation and upstream catalyst [13-14], to simultaneously convert $\mathrm{CO}, \mathrm{HCs}$ and $\mathrm{NO}_{x}$ into $\mathrm{CO}_{2}, \mathrm{H}_{2} \mathrm{O}$ and $\mathrm{N}_{2}$, respectively. Among these methods, catalysts require $20-30 \mathrm{~s}$ to reach operating temperature $\left(400^{\circ} \mathrm{C}\right)$, which causes the emission of $60-80 \%$ of HCs and CO [15]. Therefore, it is crucial to find a practical and effective method to shorten the time difference between engine cold-start and exhaust conversion.

Herein, we developed a catalyst utilizing Pd and Rh as active components, Ce-Zr solid solution as assistant, $\mathrm{y}-\mathrm{Al}_{2} \mathrm{O}_{3}$ as coating and $\mathrm{Fe}-\mathrm{Cr}-\mathrm{Al}$ as supporter, to decrease operating temperature and increase exhaust conversion efficiency. With the optimization of catalyst component and the employment of a high-frequency electrical heating method, the exhaust conversion efficiency was improved by $78 \%$.

\section{Experimental}

\subsection{Materials}

Materials included $\mathrm{Pd}\left(\mathrm{NO}_{3}\right)_{2}, \mathrm{Rh}\left(\mathrm{NO}_{3}\right)_{3}, \mathrm{HNO}_{3}, \mathrm{Ce}_{\chi} \mathrm{Zr}_{(1-x)}$ $\mathrm{O}_{2}, \mathrm{y}-\mathrm{Al}_{2} \mathrm{O}_{3}$ (Sinopharm Chemical Reagent Co., Ltd, AR); $\mathrm{Al}_{2} \mathrm{O}_{3} \cdot \mathrm{H}_{2} \mathrm{O}$ (Jiangyan Chemicals Co., Ltd, AR); Fe-Cr-Al supporter (Corning Inc.); $10 \% \mathrm{C}_{3} \mathrm{H}_{8} / \mathrm{N}_{2}, 5000 \mathrm{ppm} \mathrm{NO} / \mathrm{N}_{2}$, $5 \% \mathrm{CO} / \mathrm{N}_{2}$ (Shanghai Pujiang Special Gas Industry Co., Ltd.).

Instruments included evaluation device, vacuum extraction unit (East China University of Science and Technology); induction heater (MacDZ-10/380, Shanghai OG Electrical Co., Ltd); thermal imager (Fluke Ti2, Fluke Corporation); $\mathrm{NO}_{x}$ analyzer (Model 42i-HL, Thermo Fisher 
Scientific); gas chromatography (9790, Fuli Analytical Instrument Co., Ltd); ball miller (QM-WX04, Nanjing University); drying oven (LC-223, Shanghai Environmental Equipment Corp.); muffle furnace (KS60-63-160, Shanghai Yifeng Co., Ltd).

\subsection{Methods}

\subsubsection{Preparation}

To prepare $\mathrm{Pd}$ slurry, $\mathrm{Pd}\left(\mathrm{NO}_{3}\right)_{2}$ solution $(19.2 \mathrm{~g}$, in concentration of $10 \%), \mathrm{Al}_{2} \mathrm{O}_{3} \cdot \mathrm{H}_{2} \mathrm{O}(18.8 \mathrm{~g}), y-\mathrm{Al}_{2} \mathrm{O}_{3}(115.2 \mathrm{~g})$ and Ce-Zr solid solution $(28.8 \mathrm{~g})$ were mixed in water $(100 \mathrm{~g})$ and stirred (800 rpm, $30 \mathrm{~min}) . \mathrm{HNO}_{3}(7.4 \mathrm{~g}$, in concentration of $65-68 \%$ ) was slowly added to the solution until the $\mathrm{pH}$ reached 3-4. After adding $30.6 \mathrm{~g}$ water, the mixture was milled (1200 rpm, $2 \mathrm{~h}$ ), in which the content of oxides and $\mathrm{Pd}$ in the slurry was $50 \%$ and $0.6 \%$, respectively.

To prepare the $\mathrm{Rh}$ slurry, $\mathrm{Rh}\left(\mathrm{NO}_{3}\right)_{3}$ solution $(9.6 \mathrm{~g}$, in concentration of $10 \%), \mathrm{Al}_{2} \mathrm{O}_{3} \cdot \mathrm{H}_{2} \mathrm{O}(9.4 \mathrm{~g}), \mathrm{y}-\mathrm{Al}_{2} \mathrm{O}_{3}(57.6 \mathrm{~g})$ and Ce-Zr solid solution (14.4 g) were mixed in water (50 g) and stirred (800 rpm, $30 \mathrm{~min}$ ). $\mathrm{HNO}_{3}$ (3.7 g) was slowly added to the solution until $\mathrm{pH}$ reached 3-4. After adding $15.3 \mathrm{~g}$ water, the mixture was milled (1200 rpm, $2 \mathrm{~h}$ ), in which the content of the oxides and $\mathrm{Rh}$ was $50 \%$ and $0.6 \%$, respectively.

$\mathrm{Pd}$ and $\mathrm{Rh}$ slurries were then mixed in a designed ratio to prepare the catalyst. Fe-Cr-Al supporter was cut into 2 $\mathrm{cm} \times 2 \mathrm{~cm} \times 2 \mathrm{~cm}$ cubes, washed with a cleaning agent, rinsed with water, annealed in air $\left(750^{\circ} \mathrm{C}, 3 \mathrm{~h}\right)$, and then immersed in the mixed slurry ( $5 \mathrm{~min}$, under vacuum). The slurry-supporter composite was dried $\left(120^{\circ} \mathrm{C}, 24 \mathrm{~h}\right)$ and calcined $\left(550^{\circ} \mathrm{C}, 3 \mathrm{~h}\right)$. The standard mass of the catalyst should be $810 \pm 20 \mathrm{mg}$, and the content of oxides and metal should be ca. $100 \mathrm{~g} / \mathrm{L}$ and $1.2 \mathrm{~g} / \mathrm{L}$, respectively. If mass was lower than the standard value, a second immersion was necessary. If higher, the catalyst should be discarded.

\subsubsection{Instrumentation}

The properties of obtained catalysts were evaluated using the instruments shown in Figure 1 (thermocouple was settled at the center of catalysts). A seal test on the pipeline joint was conducted using soap solution before the mix gas was pumped in. The exhaust gas during the engine cold-start stage is composed of $\mathrm{CO}(1 \%), \mathrm{C}_{3} \mathrm{H}_{8}$ (1000 ppm), $\mathrm{NO}_{x}$ (1000 ppm), $\mathrm{O}_{2}$ (determined based on the theoretical air-fuel ratio of 14.6), and $\mathrm{N}_{2}$ (as a supplement), with a total gas flow of $1000 \mathrm{~mL} /(\mathrm{min} \cdot \mathrm{g})$.

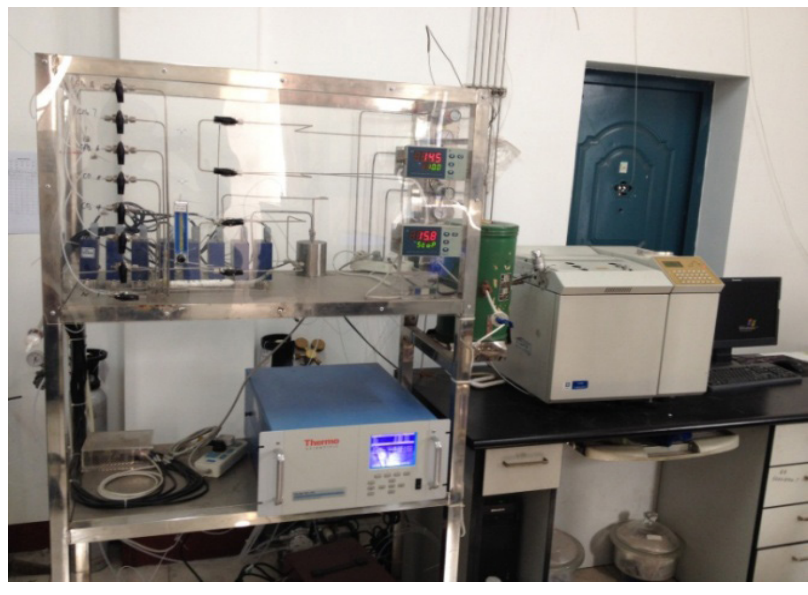

Figure 1: Evaluation device.

In the normal evaluation, the reactor was heated to the setting temperature by an electric furnace $\left(5^{\circ} \mathrm{C} / \mathrm{min}\right)$. The catalyst was rapidly heated via magnetic heating or via electrical heating. The reactants and products were taken after the reactor and remained at a settled temperature for 20 min. The concentration of $\mathrm{NO}$ and $\mathrm{NO}_{2}$ was read out from $\mathrm{NO}_{x}$ analyser, and the concentration of other gases could be calculated from the gas chromatography.

Ethical approval: The conducted research is not related to either human or animals use.

\section{Results and discussion}

\subsection{Catalyst Optimization}

The simulation exhaust gas during the engine cold-start stage is composed of $\mathrm{CO}(1 \%), \mathrm{C}_{3} \mathrm{H}_{8}(1000 \mathrm{ppm}), \mathrm{NO}_{x}$ (1000 ppm), $\mathrm{O}_{2}$ (determined based on the theoretical air-fuel ratio of 14.6), and $\mathrm{N}_{2}$ (as a supplement), with a total gas flow of $1000 \mathrm{~mL} /(\mathrm{min} \cdot \mathrm{g})$. The atom ratio of Ce:Zr, mass ratio of $\mathrm{Pd}: \mathrm{Rh}$, pore density of supporter and light-off temperature (where half of a component was transformed) was utilized to evaluate catalytic properties at low temperature (Figure 2).

Properties of catalysts with different atom ratios of Ce: $\mathrm{Zr}$ are depicted in Figure $2 \mathrm{a}$ and $2 \mathrm{~b}$. The light-off temperatures of $\mathrm{CO}, \mathrm{C}_{3} \mathrm{H}_{8}$ and $\mathrm{NO}$ decrease initially and then increase when atom ratio of Ce:Zr increases from 4:6 to 8:2. The light-off temperatures of $\mathrm{CO}$ and $\mathrm{C}_{3} \mathrm{H}_{8}$ reach the lowest point at atom ratio of 6:4 while that of $\mathrm{NO}$ reaches its minimum at the atom ratio of 7:3. The results indicate that atom ratio of Ce:Zr should be around 6:4 for the catalyst with a low light-off temperature. 
a
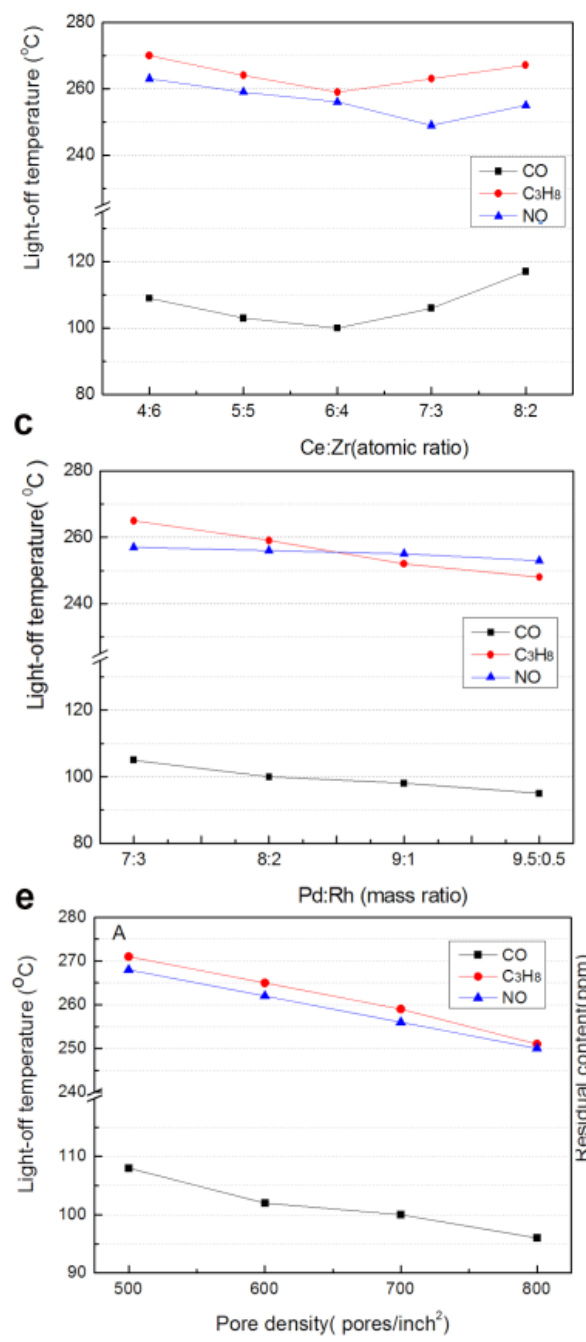

b
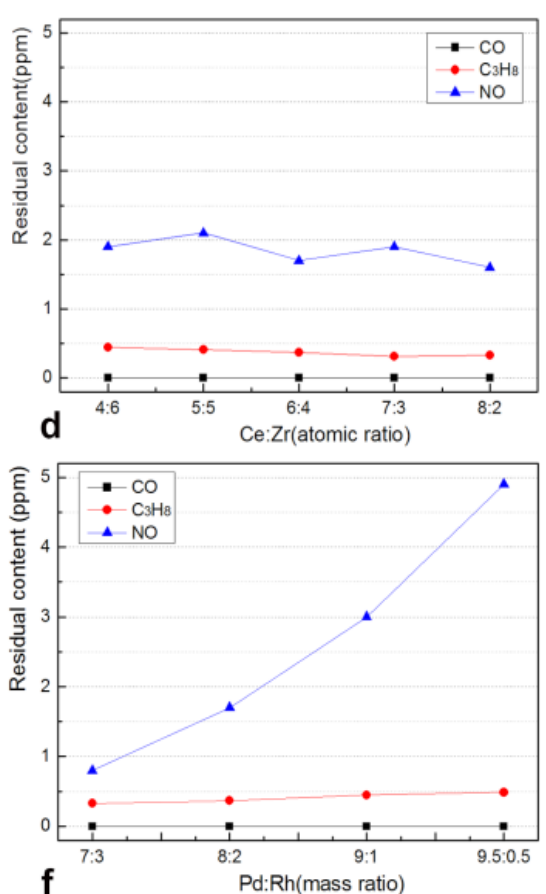

f

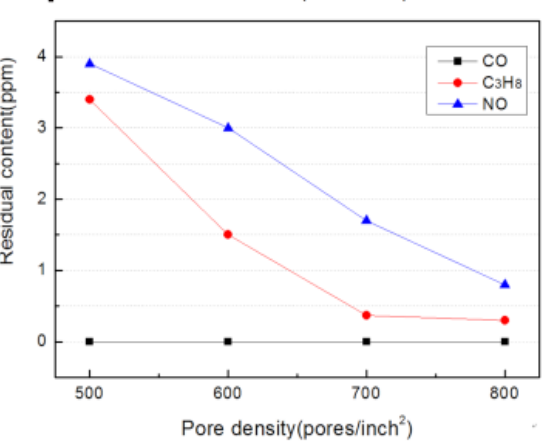

Figure 2: Effect of (a, b) Ce:Zr atom ratio, (c, d) Pd:Rh mass ratio, (e, f) pore density on light-off temperature and residual content.

Figure $2 \mathrm{c}$ and $2 \mathrm{~d}$ indicate influence of the mass ratio of $\mathrm{Pd}: \mathrm{Rh}$ on the catalytic properties while keeping the total weight of Pd and Rh at $1.2 \mathrm{~g} / \mathrm{L}$. The light-off temperatures of the catalysts for $\mathrm{CO}, \mathrm{C}_{3} \mathrm{H}_{8}$ and $\mathrm{NO}$ decrease when $\mathrm{Pd}$ content increase. This is beneficial for catalytic effect at low temperature, but the excessive increase in Pd content will reduce $\mathrm{Rh}$ content of the catalyst and make the concentration of residual NO exceed the legal emission limit. Therefore, the mass ratio of $\mathrm{Pd}$ : Rh should be in the range of 8:2 to 9:1 to both lower the light-off temperature and residual gas concentration.

Figure $2 \mathrm{e}$ and $2 \mathrm{f}$ show the effect of pore density of supporter on the catalytic property in which the mass ratio of $\mathrm{Pd}: \mathrm{Rh}$ is 8:2, atom ratio of Ce:Zr is 6:4, and total weight of Pd and Rh is $1.2 \mathrm{~g} / \mathrm{L}$. The light-off temperatures of catalysts and the concentration of residual gases decrease with the increase of pore density of supporter. The increased efficiency of exhaust conversion is attributed to the increase of contact surface area between catalyst and exhaust. However, if pore density increases excessively, pores will be too small and easily blocked by soot particles. The engine consequently cannot work stably due to the high emissions resistance in the exhaust pipe. Thus, an optimal supporter is a compromise between its pore density and its light-off temperature.

With these data in hand, we managed to determine the optimized catalyst component: atom ratio of Ce: $\mathrm{Zr}$ is 6:4, mass ratio of $\mathrm{Pd}: \mathrm{Rh}$ is $8: 2$, total weight of $\mathrm{Pd}$ and $\mathrm{Rh}$ is $1.2 \mathrm{~g} / \mathrm{L}$, pore density is 700 pores/inch ${ }^{2}$. 


\subsection{Transformation behaviour}

We sought to probe the transformation behaviour of simulation exhaust gas over the optimized catalyst. Results were recorded in Table 1 . The operating temperature is $350^{\circ} \mathrm{C}$, lower than commercial emission control catalyst with an operating temperature of $400^{\circ} \mathrm{C}$ [13]. The residual concentration is $\mathrm{CO}(0 \mathrm{ppm}), \mathrm{C}_{3} \mathrm{H}_{8}(0.37 \mathrm{ppm})$, NO (1.7 ppm) and $\mathrm{NO}_{2}(1.4 \mathrm{ppm})$, which meets the strict emission requirement.

\subsection{Fast heating method}

While the optimization of the catalyst can, to some extent, lower the light-off temperature, it is still necessary to shorten the time difference between engine cold-start and the time when catalyst reaches its operating temperature. Therefore, we took a step further to investigate two fast heating methods: magnetic heating and electrical heating.

Magnetic heating was first employed, and the catalyst could reach $350^{\circ} \mathrm{C}$ within $10 \mathrm{~s}$ (under the current of 20 $\mathrm{A})$, but there was a large temperature difference between the outer $\left(350^{\circ} \mathrm{C}\right)$ and center $\left(185^{\circ} \mathrm{C}\right)$ of the catalyst, due to the magnetic shielding effect. Thus, we utilized highfrequency electrical heating method instead. The heating experiment was conducted with a gas flow (setting temperature of $350^{\circ} \mathrm{C}$, current of $20 \mathrm{~A}$, current frequency of $21.9 \mathrm{KHz}$ and air flow rate of $6000 \mathrm{~mL} / \mathrm{min}$ ). Results indicate that both outer and center temperatures reach $350^{\circ} \mathrm{C}$ in $5 \mathrm{~s}$ with an even distribution.

The experiment of simulated exhaust gas over optimized catalyst with high-frequency electrical heating was conducted(Table2). Compared with Table1, conversion time ( $5 \mathrm{~s} v s .2 \mathrm{~h} 57 \mathrm{~min}$ ) and residual concentration of harmful nitrogen oxides, NO (0.9 ppm vs. $1.7 \mathrm{ppm})$ and $\mathrm{NO}_{2}$ (1.2 ppm vs. $1.4 \mathrm{ppm}$ ), were significantly decreased, indicating that high-frequency electrical heating of catalyst could indeed improve exhaust conversion efficiency at engine cold-start stage. The residual concentration of NO is plotted to retention time (Figure 3), which shows that conversion efficiency increases by $78 \%$ compared with traditional techniques.

\section{Conclusions}

To summarize, we developed a novel catalyst for fast removal of pollutants from engine cold-start stage. The
Table 1: Residual concentration of simulated exhaust gases over optimized catalyst.

\begin{tabular}{llllll}
\hline Time $/ \mathrm{min}$ & $\mathrm{t} /{ }^{\circ} \mathrm{C}$ & $\mathrm{CO} / \mathrm{ppm}$ & $\mathrm{C}_{3} \mathrm{H}_{8} / \mathrm{ppm}$ & $\mathrm{NO} / \mathrm{ppm}$ & $\mathrm{NO}_{2} / \mathrm{ppm}$ \\
\hline 0 & 25 & 10000.00 & 1000.00 & 1000.00 & 0.00 \\
40 & 100 & 10000.00 & 1000.00 & 870.21 & 14.01 \\
& 178 & 2.57 & 1022.74 & 642.07 & 7.11 \\
& 215 & 1.52 & 1015.85 & 698.02 & 11.01 \\
& 250 & 0.00 & 973.92 & 657.20 & 8.01 \\
& 300 & 0.00 & 98.04 & 410.30 & 6.10 \\
& 350 & 0.00 & 0.37 & 1.70 & 1.40 \\
\hline
\end{tabular}

Table 2: Residual concentration of simulated exhaust gases over optimized catalyst with high-frequency electrical heating.

\begin{tabular}{lllllll}
\hline Time $/ \mathbf{s}$ & $\mathrm{t}_{\text {outer }} /{ }^{\circ} \mathrm{C}$ & $\mathbf{t}_{\text {center }} /{ }^{\circ} \mathrm{C}$ & $\mathbf{C O} / \mathrm{ppm}$ & $\mathrm{C}_{3} \mathrm{H}_{\mathbf{8}} / \mathrm{ppm}$ & $\mathrm{NO} / \mathrm{ppm}$ & $\mathrm{NO}_{2} / \mathrm{ppm}$ \\
\hline 0 & 9 & 9 & 10000 & 1000 & 1001 & 0 \\
1 & 228 & 227 & - & - & 763 & 9 \\
3 & 349 & 347 & - & - & 131 & 11 \\
5 & 350 & 350 & 0 & 0.56 & 0.9 & 1.2 \\
\hline
\end{tabular}

$t_{\text {outer }}$ - the outer temperature of catalyst, $t_{\text {center }}$ - the center temperature of catalyst

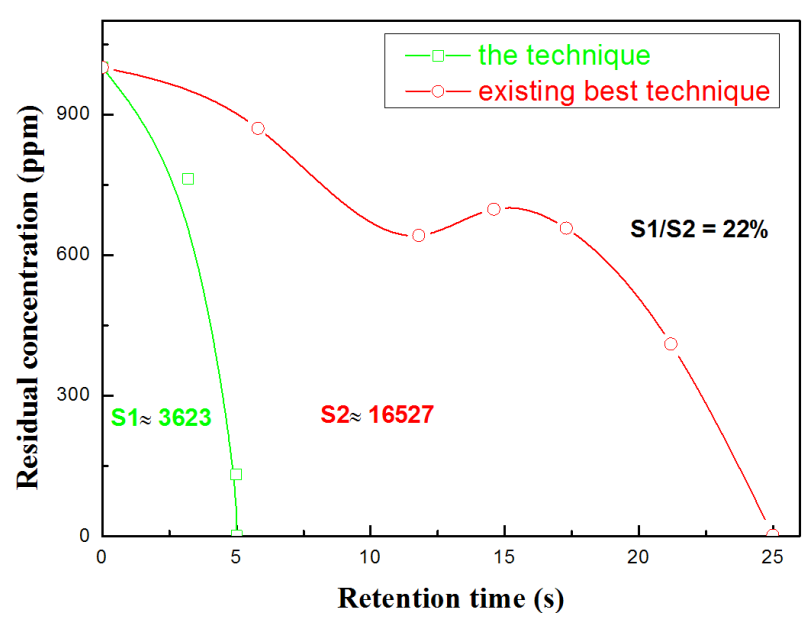

Figure 3: Comparison of NO removal effect between traditional and novel catalyst at engine cold-start stage.

catalyst was optimized to the following component: atom ratio of Ce: $\mathrm{Zr}$ is 6:4, mass ratio of $\mathrm{Pd}: \mathrm{Rh}$ is $8: 2$, total weight of $\mathrm{Pd}$ and $\mathrm{Rh}$ is $1.2 \mathrm{~g} / \mathrm{L}$, pore density is 700 pores/ inch $^{2}$ with $\mathrm{Pd}$ and $\mathrm{Rh}$ as active components, Ce-Zr solid solution as assistant, $y-\mathrm{Al}_{2} \mathrm{O}_{3}$ as coating and $\mathrm{Fe}-\mathrm{Cr}-\mathrm{Al}$ as supporter. It is corroborated that modified catalyst starts to convert pollutants in $1 \mathrm{~s}$, much faster than traditional 
catalyst which needs 20-30 s. Moreover, it can decrease operating temperature from $400^{\circ} \mathrm{C}$ to $350^{\circ} \mathrm{C}$ and improve exhaust conversion efficiency by $78 \%$ with the application of high-frequency electrical heating method. This novel catalyst is reliable and widely applicable, which provides a promising future in the advancement of exhaust conversion technique at engine cold-start stage.

Conflict of interest: Authors state no conflict of interest.

\section{References}

[1] Zhu J., Zhang L., Deng Y., Liu B., Dong L., Gao F., et al., Influence of preparation method on the catalytic activities of $\mathrm{CuO} / \mathrm{Ce}_{0.67} \mathrm{Zr}_{0.33} \mathrm{O}_{2}$ catalysts in $\mathrm{CO}+\mathrm{O}_{2}$ reaction, Appl. Catal. B-Environ., 2010, 96, 449-457.

[2] Twigg M.V., Progress and future challenges in controlling automotive exhaust gas emissions, Appl. Catal. B-Environ., 2007, 70, 2-15.

[3] Cheng Y., Liu Y., Huo M., Sun Q., Wang H., Chen Z., et al., Chemical characteristics of precipitation at Nanping Mangdang Mountain in eastern China during spring, J. Environ. Sci-China, 2011, 23, 1350-1358.

[4] Chen N., Hong H., Huang Q., Wu J., Atmospheric nitrogen deposition and its long-term dynamics in a southeast China coastal area, J. Environ. Manage., 2011, 92, 1663-1667.

[5] Tang E., Peng C., How does pollutant emission in waste gas impact on human mortality rates in Chinese geographical provinces level? Environ. Earth Sci., 2016, 75, 1259.
[6] He L.Y., Qiu L.Y., Transport demand, harmful emissions, environment and health co-benefits in China, Energ. Policy, 2016, 97, 267-275.

[7] Fan Z., Wang X., Qian Y., Liu X., Preparation and purifying efficiency of a new silicon carbide porous ceramics in auto exhaust emission control, Environ. Pollut. Control., 2009, 31, 63-66.

[8] Chu R., Zhang G., Xie H., The research of application of nanotechnology in purification automobile exhaust, Environ. Sci. Manage., 2007, 32, 111-113.

[9] Wang J., Chen H., Hu Z., Yao M., Li Y., A review on the Pd-based three-way catalyst, Catal. Rev., 2015, 57, 79-144.

[10] Guo Y., Lu G., Zhang Z., Zhang S., Qi Y., Liu Y., Preparation of $\mathrm{Ce}_{x} \mathrm{Zr}_{1-x} \mathrm{O}_{2}(x=0.75,0.62)$ solid solution and its application in Pd-only three-way catalysts, Catal. Today, 2007, 126, 296-302.

[11] He H., Yu Y., Selective catalytic reduction of $\mathrm{NO}_{x}$ over $\mathrm{Ag} / \mathrm{Al}_{2} \mathrm{O}_{3}$ catalyst: from reaction mechanism to diesel engine test, Catal. Today, 2005, 100, 37-47.

[12] He X., The study of low-temperature light-off catalysts for exhaust gas emission control, PhD thesis, Kunming University of Science and Technology, Yunnan, China, 2011.

[13] Jiang Z., Reflections on energy issues in China, J. Shanghai Jiaotong Univ. (Sci.), 2008, 13, 257-274.

[14] Heo I., Choung J.W., Kim P.S., Nam I.S., Song Y.I., In C.B., et al., The alteration of the performance of field-aged Pd-based TWCs towards $\mathrm{CO}_{\text {and }} \mathrm{C}_{3} \mathrm{H}_{6}$ oxidation, Appl. Catal. B-Environ., 2009, 92, 114-125.

[15] Aparicio M.S.L., Canafoglia M.E., Ocsachoque M.A., Lick I.D., Botto I.L., Co-Rh modified natural zeolites as new catalytic materials to oxidize propane and naphthalene from emission sources, Open Chem., 2016, 14, 335-342. 